\title{
Quantitative Assessment of Career Growth of Chinese Army
}

\author{
Zhang Li, Zhao Ning, Chen Long, Zhang Zhen Duo
}

School of Management, Harbin Institution of Technology, Harbin, China

\section{Email address:}

zhanglihit@hit.edu.cn (Zhang Li)

\section{To cite this article:}

Zhang Li, Zhao Ning, Chen Long, Zhang Zhen Duo. Quantitative Assessment of Career Growth of Chinese Army. Psychology and Behavioral Sciences. Vol. 6, No. 4, 2017, pp. 49-53. doi: 10.11648/j.pbs.20170604.11

Received: May 31, 2017; Accepted: June 13, 2017; Published: July 13, 2017

\begin{abstract}
This study proposed that career growth is a two-dimension construct including quantitative career growth and qualitative career growth. Quantitative career growth denoted the growth rate of job feature such as remuneration and promotion, and qualitative career growth denoted the value of the job changes in current organization. This study examined the two-dimension construct of career growth by collecting 1106 questionnaires in Chinese military institutions. The results supported the two-dimension model of career growth.
\end{abstract}

Keywords: Quantitative Career Growth, Qualitative Career Growth, Scale Development

\section{Introduction}

Organizational restructuring and globalization have become pervasive. These emerging realities have given rise to a "boundaryless" model for the work environment [1]. In this new model of professional life, employees seek to achieve personal and professional growth through working in a variety of firms. To enhance their employability, workers focus on the career growth opportunity offered by prospective employers. Moreover, the third Plenary Session of 18 th CPC (Communist Party of China) Central Committee proposed to establish the military officer professionalism system and gradually form a scientific and standardized military cadres' system. Besides, in the Chinese context, increasing military personnel come across career bottleneck after certain years and they have to transfer to civilian work. Therefore, research on the career growth of Chinese military personnel can respond to the advocacy of establishing the military officer professionalism system and help military personnel to cope with the potential stress of transferring to civilian work.

But a lack of proper scale is a key limitation to the development of researches about career growth in Chinese army. First as to the objectives, most of career growth scales are only suitable for managers. For example, Tharenou (2001) used the "control range", "promotions" and "salary growth" to measure the management personnel occupation growth, while these indicators could not reflect the technical workers' career growth brought by their professional skills development [2]. Secondly, in terms of the contents, most of the scales focused on a certain aspect of career growth. Nkereuwem (1996) regarded the prospective of career growth as obtaining higher positions in organizations, ignoring promotion and the increase of salary [3]. Finally, Weng and Xi (2010) proposed a scale to solve the two problems shown above [4], but the scale was not robust. Weng and Xi (2011) considered career growth was consisted by 4 factors, goal progress, ability development, promotion and wage increase [5]. But because of strong correlation between promotion and wage increase, Weng and McElroy (2012) united the two dimensions into one called organizational reward [6].

So, in this research, the construct of career growth is divided into two dimensions, qualitative career growth and quantitative career growth. Based on the existing researches and empirical study, the aim of this study is to develop a career growth scale suitable for Chinese military personnel.

\section{Literature Review}

Career growth, according to Graen et al. (1997), denotes to personal speed of moving among a series of jobs which are valuable for the focal person and it is an incremental concept [7]. However, Graen et al. (1997) did not provide appropriate tool to make this concept operationalization [7]. Later, Weng and $\mathrm{Hu}$ (2010) redefined career growth within the 
organizations as the career goal progress, professional ability development, promotion speed, and remuneration growth in the present organizations [8]. They constructed a scale to operationalize this concept. Unfortunately, the four-dimension scale of career growth was not robust. Weng and McElroy (2012) applied this scale to measure the career growth of the managers in a wide range of industries (such as high technology, manufacturing, and business services et al.) [6]. As promotion speed and remuneration growth were highly correlated, Weng and McElroy (2012) integrated these two dimensions into one factor [6]. The results of the confirmatory factor analysis showed that the three-factor model containing career goal progress, professional ability development and organizational reward fitted the data better. Hence, more studies should be done to clarify the concept of career growth and operationalize this construct.

Deconstructing the definition of Graen et al. (1997), it can be found that career growth contains two aspects [7]. The first element is the personal speed of moving among a series of jobs and it can be descried by using objective and quantitative number (e.g. How many jobs have focal person replaced during certain period?). The second element is the personal subjective evaluation for the job mobility and it denotes individual's subjective feelings about these changes (e.g. whether the job mobility can help focal person to reach career goal). This definition is more appropriate for the career growth between organizations [8]. Similar to this definition, career growth within an organization can be defined as a two-dimension construct including the speed of job feature change in current organization and the expected utility of present work. Weng and Hu's (2009) four-dimension definition of career growth can also be simplified into two dimensions in this study [8]. First, as career goal progress is related to personal expectation about their development and it is subjective, it can be clarified into the expected utility of present work. Second, changes of job features including remuneration and promotion, promotion speed and remuneration growth can be described as the speed of job features change in current job. In addition, Chinese military organizations generally set managerial position (e.g. administration and human resource) and technical position (e.g. associate professor and assistant professor which can reflect individual's professional skill). And the promotion of technical position is overlapped with professional ability development in Weng and Hu's (2009) definition. Different from previous study which mainly focused on the promotion of managerial position [9], this study will involve the promotion of technical position and regard the promotion of technical position as the speed of job features change in current organization. Therefore, integrating the definition of Graen et al. (1997) and Weng, et al. (2009), career growth within military organization is defined as a two-dimension concept $[7,8]$.

Evidence from the perspective of measurement of career growth also supports the two-dimension model. Career growth in previous studies is measured by two sets of criteria. The first set of criteria includes employees' remuneration growth, the speed of promotion through technical and management positions and the growth in numbers of subordinates [2-3, 9-10]. All of these indicators reflect the context of development related to current job features. The main characteristic of these criteria is that they are measured by objective and quantitative indicators. Thus, it is suggested to name this kind of career evaluation as "quantitative career growth". In contrast, the second set of criteria is based on employees' evaluations of their own development in relation to their work and the expected utility of their present work for future goals $[11,12]$. These career evaluations are subjective and future-oriented. Therefore, we propose describing this approach as "qualitative career growth". To summarize, this research will develop a career growth scale which is applicable for Chinese military personnel and examine the two-dimension construct of career growth following the procedure of previous researches $[13,14,15]$.

\section{Methods and Design}

\subsection{Participants}

A self-reported scale was administrated to test our hypotheses. The data were collected from members of military units in China. To protect confidentiality, questionnaires were sent in a paper-and-pencil format and the participants omitted their identification numbers from the questionnaires. The questionnaires were firstly sent to HR managers, who then allocated the questionnaires to the participants. 1106 valid questionnaires were received from 1207 submitted questionnaires, for a questionnaire efficiency of $91.6 \%$. Overall, $73.4 \%$ of the respondents are male and $39.5 \%$ are married. The average age of the respondents is 34.09 $(\mathrm{SD}=7.69)$. Among the respondents, 53\% have Master's degrees or above, $42.2 \%$ of them have Bachelor's degrees and the remainders have lower levels of education. Some $7.8 \%$ of the participants hold management positions. The average organizational tenure of the respondents is 9.81 years $(\mathrm{SD}=7.91)$, and their average total job experience is 12.72 years $(\mathrm{SD}=9.1)$.

\subsection{Questionnaires}

This research follows the procedure of Collins and Smith (2006) to differentiate and validate measures of quantitative and qualitative career growth [15]. Existing measures have been looked over in the career growth literature and an item pool was created. The scale of Weng and Hu (2009) contains the items which is not applicable for this study such as "My present job position is more ideal than that in the previous organization" [8]. As the employees who have not change the work units are unable to fill out this item, some items of this scale are excluded. Besides that, the overlapped items among these scales are also omitted and finally we obtain six original items.

Then, seven staffs from military organization were interviewed concerning the indicators representing technical career advancement, and majority of them are senior engineers 
and managers. The age of the interviewees ranges from 30 to 60 , and the organizational tenure ranges from 2 to 42 years. All of these interviewees mentioned that the army units assigned technical positions to employees who wanted to be technical experts. Furthermore, four of the interviewees suggested that the number of apprentices an employee coached was the main indicator of their technical ability. Consequently, measures were added concerning promotions of technical positions and numbers of apprentices as the indicators of quantitative career growth. Following the type of describing indicators devised by Weng and Xi (2010), the original items were revised based on these two phenomena [4]. Specifically, the item "Compared with the colleagues, the advancements in my management position are speedy" was changed into "Compared with my colleagues, the advancements in my management position or technical position are speedy", and the item "Compared with my colleagues, the number of my subordinates has grown larger" was changed into "Compared with my colleagues, the number of my subordinates or apprentices has grown larger". We used a five-point scale ranging from "strongly disagree" to "strongly agree" and investigate two samples to validate this measure.

\section{Results}

Exploratory factor analysis and confirmed factor analysis were used to test the structure of career growth. In this study, the samples were divided into two parts randomly, and each one contained 548 samples. And there was no differences between the two parts in age, gender, and education background.

\subsection{Exploratory Factor Analysis}

The result of Bartlett Test is $2185.02(\mathrm{P}<0.001)$ and KMO is 0.79 , indicating that the data can be used to conduct exploratory factor analysis. By the method of principle component analysis with varimax rotation, the six items can be divided into two factors which explain $81.98 \%$ of the common variance among items. Four items load on the first factor, and explain $52.25 \%$ of the common variance among items. Two items load on the second factor and explain $29.72 \%$ of the common variance among items. The factor loading in the specific factors are all larger than 0.4 as is shown in Table 1. The first factor is named as quantitative career growth and the second factor is named as qualitative career growth.

Table 1. Factor Loadings for Exploratory and Confirmatory Factor Analysis.

\begin{tabular}{|c|c|c|}
\hline \multirow[b]{2}{*}{ Measurement } & \multicolumn{2}{|l|}{ Loadings } \\
\hline & $\begin{array}{l}\text { Quantitative } \\
\text { career growth }\end{array}$ & $\begin{array}{l}\text { Qualitative } \\
\text { career growth }\end{array}$ \\
\hline Compared with my colleagues, the increase of my salary is rapid & 0.88 & 0.09 \\
\hline Compared with my colleagues, the advancements in my management position or technical position are speedy & 0.92 & 0.16 \\
\hline Compared with my colleagues, the number of my subordinates or apprentices has grown larger & 0.85 & 0.13 \\
\hline Compared with my colleagues, I get more promotions & 0.9 & 0.12 \\
\hline My present job is relevant to the growth and development in my career & 0.13 & 0.93 \\
\hline Common Variance & $53.10 \%$ & $29.90 \%$ \\
\hline
\end{tabular}

\subsection{Confirmed Factor Analysis}

A confirmatory factor analysis was conducted by using the second sample. The results of the confirmatory factor analysis show that the two-dimension model fits the data well $\left(\chi^{2}=22.0\right.$, $d f=8, \quad G F I=0.98, T L I=0.99, \quad C F I=0.99, \quad R M R=0.02$, $R M S E A=0.06$ ). Therefore, the confirmatory factor analysis

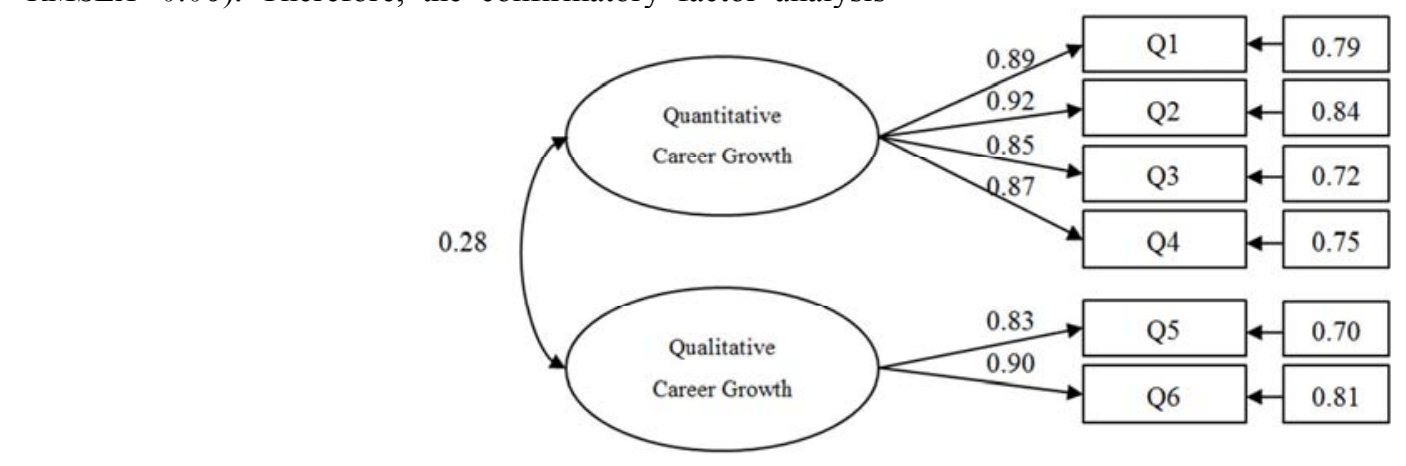

Figure 1. Results of confirmed factor analysis. provides discriminant validity to our two subscales. These two scales yielded Cronbach's $\alpha$ scores of 0.91 and 0.91 respectively which indicate high reliability of the two subscales. In summary, the pilot study provides support for the two-dimension model of career growth including quantitative and qualitative career growth. As shown in Figure 1, the standardized load coefficients are
bove 0.8 and are significant at the level of 0.001 . As to the quantitative career growth, the AVE equals 0.78 and CR is 0.93. As to the qualitative career growth, the AVE equals 0.75 and $\mathrm{CR}$ is 0.86 . This result shows that all dimensions of career growth have excellent convergent validity.

\subsection{Reliability Analysis}

Half split reliability and Cronbach's $\alpha$ were used to make 
sure the scale exact and reliable.

Table 2. Reliability of Career Growth Scale.

\begin{tabular}{llll}
\hline Reliability & Total Items & Quantitative Career Growth & Qualitative Career Growth \\
\hline Cronbach's $\alpha$ & 0.848 & 0.926 & 0.86 \\
Split half Reliability & 0.739 & 0.915 & 0.86 \\
\hline
\end{tabular}

As shown in table 2, the Cronbach's $\alpha$ of career growth scale is 0.848 and the split half reliability is 0.739 . As to the two sub-scales, both the Cronbach's $\alpha$ and split half reliability are bigger than 0.7 , which indicates that the career growth scale has convincible reliability and can be used in the academic researches.

\section{Discussion}

Two samples from Chinese military organizations were used to develop the scale of career growth and examine the conceptual distinction between quantitative and qualitative career growth. Quantitative career growth is the velocity of advancement of present job features such as salary, promotions and numbers of subordinates or apprentices. In contrast, qualitative career growth is the expected value of present work for the future.

The results of this study play an important role in understanding the internal structure career growth and providing a practical tool to support other career growth researches. This research focuses on measuring career growth in the organization, including two aspects: career growth speed and career growth utility. In essence, it is very similar to the definition given by Latack and Dozier (1986) to career growth associated with job loss. They divided career growth into two distinct dimensions ${ }^{[16]}$. One is the benefits brought by new job is higher than the loss brought by quitting the old job. The other dimension is the satisfaction towards the new job, which is the subjective value of the job. But this division is abstract which cannot be used in academic researches.

In this article, the concept of career growth is made specific and operational. The speed of career growth is represented by promotion, increase of followers and rise of wages. And career goal and effects of recent jobs on professional life are used to represent the utility of current job. And a convincible scale is developed to operate the two-dimension definition of career growth, which can be applied in related researches. In order to make sure that the scale is exact and reliable, the process come up with by Collins and Smith is adopted, and advices from HR managers in Chinese military organizations are taken to revise the items, which make the scale matched with the actual situation of Chinese army.

\section{Conclusion}

In this study, two-dimension structure of career growth is put up with, and statistical methods is used to test the structure. Results show that our two-dimension career growth scale is exact and reliable, which can be applied in related researches.

And this research also can provide management implications to $\mathrm{HR}$ managers in Chinese military organizations. The career growth can facilitate the Chinese military personnel to cope with the career bottleneck which may occur after the military personnel having served the nations for some certain years. When HR adopt promotion, and rise of wages as incentives to motivate workers to perform better, they should also consider the meaning of this employee-prompting means to the workers. Enterprises can increase workers' expectations towards their work and organizations through providing trainings concerning career management and organizational development plan.

\section{Acknowledgement}

Supported by the National Natural Science Foundation of China (71472054).

\section{References}

[1] Bennett, D., Roberts, L., Ananthram, S, Broughton, M, "What is required to develop career pathways for teaching academics," Higher Education, pp 1-16, 2017.

[2] Tharenou, P, "Going up? Do traits and informal social processes predict advancing in management," Academy of Management Journal, vol 44, pp. 1005-1017, 2001.

[3] Nkereuwem E E, “Job performance attributions and career advancement prospects for women in the academic libraries," Librarian Career Development, vol 4, pp. 18-24, 1996.

[4] Weng, Q., Xi, Y., “A literature review of employees' career growth," Forecasting, vol 6, pp.1-7, 2010.

[5] Weng, Q., Xi, Y, "Career Growth Study: Scale development and validity test," Management Review, vol 23, pp. 132-143, 2011.

[6] Weng Q, McElroy J C, “Organizational career growth, affective occupational commitment and turnover intentions," Journal of Vocational Behavior, vol 80, pp. 256-265, 2012.

[7] Graen, G. B., Chun, H., Dharwadkar, R., Grewal, R., Wakabayashi, M, "Predicting speed of managerial advancement over 23 years using a parametric duration analysis: A test of early leader-member exchange, early job performance, early career success, and university prestige," Best papers proceedings: Making global partnerships work association of Japanese business studies, pp. 75-89, 1997.

[8] Weng, Q., Hu, B, “The structure of career growth and its impact on employees' turnover intention”, Industrial Engineering and Management, vol 1, pp. 14-21, 2009. 
[9] Okumus, F., Karamustafa, K., Sariisik, M., Ulama, S, Turkay, $\mathrm{O}$, "Career paths of hotel general managers in Turkey," Asia Pacific Journal of Tourism Research, vol 21, pp 1214-1226, 2016.

[10] Chen, J. Q., Hou, Z. J., Li, X., Lovelace, K. J., Liu, Y. L., Wang, Z. L, "The Role of Career Growth in Chinese New Employee's Turnover Process," Journal of Career Development, vol 43, pp 11-25, 2016.

[11] McElroy, James C., Qingxiong Weng, "The connections between careers and organizations in the new career era: Questions answered, questions raised," Journal of Career Development, vol 43, pp 3-10, 2016.

[12] Bennett, Misty M., Terry A. Beehr, Lawrence R. Lepisto. "A Longitudinal Study of Work After Retirement: Examining Predictors of Bridge Employment, Continued Career Employment, and Retirement," The International Journal of Aging and Human Development, vol 83, pp 228-255, 2016.
[13] Seibert, Scott E., Maria L. Kraimer, Peter A. Heslin, "Developing career resilience and adaptability," Organizational Dynamics, vol 3, pp 245-257, 2016.

[14] Dickinson, J., Abrams, M. D., Tokar, D. M., “An examination of the applicability of Social Cognitive Career Theory for African American college students." Journal of Career Assessment, vol 25, pp 75-92, 2017.

[15] Collins, C. J., Smith, K. G, "Knowledge exchange and combination: The role of human resource practices in the performance of high-technology firms," Academy of Management Journal, vol 49, pp. 544-560, 2006.

[16] Latack J C, Dozier J B, “After the ax falls: job loss as a career transition", Academy of Management Review, vol 11, pp.375-392, 1986. 